Original Research Article

\title{
A study of efficacy and safety of intravenous iron sucrose for the treatment of moderate anaemia in antenatal women in South India
}

\author{
Venkata Ramana Vundi ${ }^{1}$, Madhavi Pudutha ${ }^{2}$, Chandrakala Kambar ${ }^{3 *}$
}

${ }^{1}$ Department of Pharmacology, Siddhartha Medical College, Vijayawada, Andhra Pradesh, India

${ }^{2}$ Department of Pharmacology, Osmania Medical College, Hyderabad, Telangana, India ${ }^{3}$ Department of Pharmacology, Guntur Medical College, Guntur, Andhra Pradesh, India

Received: 20 April 2017 Accepted: 16 May 2017

*Correspondence to:

Dr. Chandrakala Kambar, Email: chandook2@gmail.com

Copyright: (C) the author(s), publisher and licensee Medip Academy. This is an openaccess article distributed under the terms of the Creative Commons Attribution NonCommercial License, which permits unrestricted noncommercial use, distribution, and reproduction in any medium, provided the original work is properly cited.

\begin{abstract}
Background: Iron deficiency anaemia in pregnancy is a common medical problem throughout India with the burden of disease impacting on both mother and the newborn. The WHO technical group working on the prevention and treatment of anaemia has documented that parenteral iron therapy has produced a rapid and better correction of iron deficiency anaemia.

Methods: A total of 61 antenatal women in the age group of 18-25yrs were enrolled and randomly assigned into study group. For a period of 4 weeks, study group received iron sucrose intravenously. The results were noted, tabulated, analysed and expressed as descriptive statistics. Student's ' $t$ ' test and percentages were compared using chi square test. $\mathrm{P}$-value, $<0.001$ was considered significant. The results were analysed by using SPSS V-21 software. Results: Mean rise of $\mathrm{Hb}$ was $2.51 \pm 0.44$ with IV iron sucrose this was highly significant (HS). Mean rise of MCV was 8.02 \pm 6.72 with IV iron sucrose this was not significant (NS). Mean rise of PCV was5.7 \pm 2.77 with IV iron sucrose. These findings showed improvement in $\mathrm{Hb}$ and PCV which were statistically highly significant (HS). Adverse effects were $14 \%$ in the group.

Conclusions: The present study proved that iron sucrose when given intravenously there was a rapid improvement in anaemia. IV iron sucrose was proved to be safe with minimal side effects.
\end{abstract}

Keywords: Haemoglobin, Iron deficiency anaemia, Mean corpuscular volume, Packed cell volume

\section{INTRODUCTION}

Iron deficiency anaemia in pregnancy is a common medical problem throughout India with the burden of disease impacting on both mother and the newborn. Anaemia affects nearly half of all pregnant women in the world. ${ }^{1}$ In India up to $88 \%$ of pregnant women are affected with anaemia. ${ }^{2}$ Among these, $50 \%$ of anaemia in pregnancy is due to iron deficiency. ${ }^{3}$ The high prevalence of iron deficiency anaemia among women during pregnancy in developing countries is of concern and a cause of considerable morbidity and mortality.
Anaemia is estimated to contribute to $20 \%$ of all maternal deaths and $9 \%$ of peri-natal mortality. ${ }^{4-6}$ There is $2-3$ fold increase in peri-natal mortality when Haemoglobin is less than $8 \mathrm{gm} / \mathrm{dl}$ and $8-10$ fold increase when maternal haemoglobin falls below $5 \mathrm{gm} / \mathrm{dl}^{7}$ Anaemia results in increased number of preterm births, IUGR, PPH, failure of lactation and increased risk of infections in post partum period. ${ }^{8}$ Hence prevention and correction of anaemia during pregnancy is vital for safe motherhood. 
Iron deficiency anaemia exists since many years. Oral iron has been the first line of treatment for treating anaemia during pregnancy, but a considerable number of patients did not improve because of reasons like intolerance to oral iron, inadequate absorption, and side effects leading to non compliance due to which treatment becomes inadequate and in such conditions parenteral Iron therapy is preferred.

According to World Health Organisation (WHO), oral iron preparations have been proved to be inadequate to reduce frequency of Iron deficiency anaemia. Many antenatal women have been observed to be iron deficient despite routine use of iron prophylaxis adopted by health centres in developing countries. The WHO technical group working on the prevention and treatment of anaemia has documented that parenteral iron therapy has produced a rapid and complete correction of iron deficiency anaemia than oral iron therapy. ${ }^{1}$

Among all the parenteral iron preparations available, Iron sucrose appears to be efficient because of its good safety record and it overcomes the problems of absorption and compliance compared to iron dextran, iron gluconate and also blood transfusion. ${ }^{9,10}$

Iron sucrose can correct anaemia, reduce maternal morbidity and promote better neurological development of new born/infants and improve the health status of women.

\section{Pharmacology of iron sucrose $e^{11}$}

Chemical Formula: $\left[\mathrm{Na}_{2} \mathrm{Fe}_{208}(\mathrm{OH})_{3}\left(\mathrm{H}_{2} \mathrm{O}\right)\right]$ n. $\mathrm{m}\left(\mathrm{C}_{12} \mathrm{H}_{22}\right.$ $\left.\mathrm{O}_{11}\right)$

Iron sucrose is a brown, sterile, aqueous complex of polynuclear iron (III) hydroxide in sucrose containing $20 \mathrm{mg}$ elemental iron per ml. The sterile solution has an osmolarity of $1250 \mathrm{mosm} / \mathrm{l}$. The product does not contain preservatives.

Molecular wt: 34,000 - 60,000daltons, pH: 10.5 - 11.1 .

\section{Mechanism of action}

Following intravenous administration, it is dissociated into iron and sucrose by reticuloendothelial system and iron is transferred from the blood into pool of iron in the liver and bone marrow. Ferritin sequesters iron in a nonionic form from which iron is easily available.

\section{Pharmacokinetics}

Its iron component exhibits first order kinetics. Elimination $t_{1 / 2}$ is $6 \mathrm{hrs}$. Total clearance is 1.2 litres/hour. Non steady state apparent volume of distribution is 10 litres. Steady state apparent volume of distribution is 7.9 litres.

\section{Bioavailability}

Radioactive studies after iron sucrose injection in animals and humans show:

- High level of radioactivity within 5 minutes, not only in liver but also in bone marrow indicates high concentration of iron reaching bone marrow.

- Distribution curves of radioactive iron in different organs show that iron is eliminated from circulation while it is being taken up by liver and bone marrow tissues. These results indicate that iron from iron sucrose is rapidly available for erythropoiesis.

\section{Distribution}

In healthy adults, the iron component of iron sucrose gets distributed in blood and to some extent in extra cellular fluid.

\section{Elimination}

After intravenous administration, it is dissociated into iron and sucrose by the reticulo endothelial system. The sucrose component is eliminated mainly by urinary excretion. $68.3 \%$ of the sucrose is eliminated in urine in 4 $\mathrm{h}$ and $75.4 \%$ in $24 \mathrm{~h}$.

\section{Side effects}

Headache, fever, chills, pain, asthenia, malaise, thrombophlebitis, hypotension. Interactions It should not be administered concomitantly with oral iron preparation, since the absorption of oral iron may be reduced.

\section{Contraindications}

- $\quad$ Evidence of iron over load.

- Anaemia not caused by iron deficiency

- Known hypersensitivity to I.V iron sucrose (or) any of its inactive compounds.

\section{Method and route of administration ${ }^{12}$}

No test dose is required. Administered as either a bolus undiluted over $5-10 \mathrm{~min}(1 \mathrm{ml} / \mathrm{min})$ on outpatient basis (Rapid push). Infusion for a short duration of $30 \mathrm{~min}$, $200 \mathrm{mg}$ in $200 \mathrm{ml}$ of Normal Saline only (as other crystalloids cause precipitation or drug interaction) at a rate of $6 \mathrm{mg} / \mathrm{min}$ immediately after dilution. Maximum cumulative doses $1600 \mathrm{mg}$ in pregnancy $(200 \mathrm{mg}$ twice per week to a target $\mathrm{Hb}$ of $11 \mathrm{~g} / \mathrm{dl}$ or for a maximum of 4 weeks), mean treatment duration is 21 days.

\section{Supply and storage}

Supplied as $5 \mathrm{ml}$ single dose ampoule, contains $100 \mathrm{mg}$ of elemental iron $(20 \mathrm{mg} / \mathrm{ml})$ that is packaged in carton containing 10 single dose ampoules. Stored at $25^{\circ} \mathrm{C}$. 
Excursions permitted to $15-30^{\circ}$. Trade name of iron sucrose used in this study is Orofer-S.

Iron deficiency anaemia in pregnancy needs to be corrected because of its related morbidity and mortality. The objective of this study was to compare the efficacy and adverse effect profile of oral iron and intravenous iron sucrose, used for the treatment of moderate anaemia in antenatal women.

The study was prospective and interventional and was carried out in antenatal women of gestational age (28$32 \mathrm{wks}$ ) and with moderate anaemia i.e., Haemoglobin less than $8 \mathrm{gm} \%$. After obtaining an informed consent, the study was carried out in patients attending antenatal checkups at the outpatient department of Obstetrics and Gynaecology, Government General Hospital, Vijayawada, Andhra Pradesh.

\section{METHODS}

The present study was taken up to compare and evaluate the efficacy and adverse effects profile of intravenous iron sucrose used for treatment of moderate anaemia in antenatal women attending antenatal outpatient department in Government General Hospital, Vijayawada.

An informed consent was obtained from all antenatal women enrolled for the study in local language. Sample size was 50 antenatal women. The study was a prospective and interventional study. Total duration of the study was 6 months.

\section{Inclusion criteria}

- $\quad$ Singleton pregnancy with gestational age of 20-28 weeks.

- $\quad$ First and second gravida attending antenatal OP.

- Hemoglobin concentration of more than $8 \mathrm{gm}$ and less than $10.5 \mathrm{gm}$ (moderate anemia).

\section{Exclusion criteria}

- Pregnancy associated with medical problem like Diabetes, Heart Disease, renal and hepatic disorders.

- Obstetrical complications like PIH, APH etc.

- Pregnancy with anaemia other than iron deficiency, like medical and surgical causes of bleeding.

- Antenatal women with multiple pregnancy.

\section{Materials used for the study}

A total of 61 antenatal women in the age group of 18$25 y r s$ were enrolled and assessed for eligibility to participate in the study. Out of them, 11 women failed to meet the inclusion criteria and were excluded.

Investigations like complete Haemogram, with all indices -Haemoglobin (Hb\%), Packed Cell Volume (PCV), Mean corpuscular Volume (MCV), M.C.H.C, Reticulocyte count, Platelet count, Liver Function Tests, Serum Creatinine, Blood Urea, Bleeding Time, Clotting Time, and Random Blood Sugar (RBS) and Ultrasonography (USG) to rule out exclusion criteria. Thorough history was elicited and clinical examination was done. 50 Antenatal women were assigned into the study group. An informed consent was taken from each woman before the study. Study group received iron sucrose intravenously, the dose was calculated using the following formula,

$2.4 \times \mathrm{Hb}$ deficit in $\mathrm{gm} \% \mathrm{x}$ body weight in kgs+500mg. ${ }^{12,13} 500 \mathrm{mg}$ was to replenish iron reserves.

\section{Example}

Target $\mathrm{Hb}$ was $12 \mathrm{gm} \%$ so, for an antenatal woman with $\mathrm{Hb} 8 \mathrm{gm} \%$ and weight $50 \mathrm{kgs}$ the calculation was done as follows:

\section{$2.4 \times(12-8) 50+500=980 \mathrm{mg}$}

Thus obtained dose is given in divided doses, 200mg each time with minimum $48 \mathrm{hrs}$ apart. Each ml contains $20 \mathrm{mg}$ of elemental iron. Every $5 \mathrm{ml}$ of it is dissolved in $100 \mathrm{ml}$ of $0.9 \%$ of Normal saline per day; maximum of $200 \mathrm{mg}$ infusion was given.

All these antenatal women were reviewed after 4 weeks and they were enquired about compliance and adverse effects and the haematological investigations were repeated to know the post treatment response.

\section{Statistical methods}

The results were noted, tabulated, analysed and expressed as descriptive statistics. Students paired t test has been used to find the significance of rise in blood indices within the study groups before and after treatment. Percentages were compared using chi square test. P value, $<0.001$ was considered significant.

\section{Statistical software}

Microsoft word and Excel have been used to generate tables and graphs.

The results were analysed by using SPSS V-21 software.

\section{RESULTS}

The study was conducted in Department of Obstetrics and Gynaecology Government General Hospital (GGH), Siddhartha Medical College, Vijayawada, Andhra Pradesh. The aim of the study was to see the effect of intravenous iron sucrose in terms of safety, efficacy and compliance of intravenous sucrose used for the treatment of iron deficiency anaemia (moderate anaemia) in antenatal women of gestational age around 24-32 weeks. 
All these women received IV iron sucrose as per the formula.

The results were compared as rise in Blood indices, before and after taking I.V Sucrose. Then finally the mean rise in Blood indices like $\mathrm{Hb}, \mathrm{MCV}$ and Heamatocrit (PCV) were compared from baseline. The adverse effect profile of Intravenous iron sucrose was found to be less.

Table 1: Demographic data.

\begin{tabular}{|l|llll|}
\hline Parameter & Minimum & Maximum & Mean & SD \\
\hline Weight & 40 & 64 & 48.08 & 5.50 \\
\hline Age & 20 & 24 & 22.12 & 1.04 \\
\hline $\begin{array}{l}\text { Gestational } \\
\text { age }\end{array}$ & 24 & 32 & 29.52 & 2.04 \\
\hline
\end{tabular}

Demographic data was tabulated and shown in appropriate table (Table 1). Distribution of gravidity in the study group was shown in Table $2.56 \%$ were Primi gravida. There was $11.5 \%$ increase in MCV with IV iron sucrose. This is highly significant (HS) as shown in Table 3. Mean haemoglobin was $8.16 \mathrm{~g} \%$ before treatment and $10.66 \mathrm{~g} \%$ after treatment and therefore a rise by $2.5 \mathrm{~g} \%$ in 4 weeks. This is statistically highly significant (HS) as shown in Table 4. Mean PCV was 26.36 before treatment and raised to 32.06 after treatment. This is highly significant (Table 5).

Table 2: Distribution of gravidity in both groups.

\begin{tabular}{|lll|}
\hline Gravida & Number & Percentage \\
\hline PRIMI & 28 & $56.00 \%$ \\
\hline G-2 & 22 & $44.00 \%$ \\
\hline G-3 & 0 & $0 \%$ \\
\hline Total & 50 & $100.00 \%$ \\
\hline P value & [Chi-square value=39.12] & $<0.01$ \\
\hline
\end{tabular}

Table 3: Distribution and comparison of MCV before and after treatment.

\begin{tabular}{|c|c|c|c|c|c|c|c|c|}
\hline Group & At & Minimum & Maximum & Mean & SD & Paired t-value & P-value & $\%$ \\
\hline & Before treatment & 56 & 78 & 69.7 & 5.73 & \multirow{2}{*}{-8.44} & \multirow{2}{*}{$\begin{array}{l}<0.01 \\
\mathrm{HS}\end{array}$} & \\
\hline & After treatment & 70 & 86 & 77.72 & 3.88 & & & $11.5 \%$ \\
\hline
\end{tabular}

Table 4: Distribution and comparison of mean haemoglobin before and after treatment.

\begin{tabular}{|c|c|c|c|c|c|c|c|c|}
\hline Group & $\mathbf{A t}$ & Minimum & Maximum & Mean & SD & Paired t-value & P-value & $\%$ \\
\hline \multirow{2}{*}{ IV Sucrose } & Before & 7.4 & 8.8 & 8.16 & 0.33 & \multirow{2}{*}{-40.01} & \multirow{2}{*}{$\begin{array}{l}<0.01 \\
\text { HS }\end{array}$} & \\
\hline & After & 10.2 & 12 & 10.66 & 0.39 & & & $30 \%$ \\
\hline
\end{tabular}

Table 5: Distribution and comparison of mean PCV (haematocrit) before and after treatment.

\begin{tabular}{|c|c|c|c|c|c|c|c|c|}
\hline Group & $\mathbf{A t}$ & Minimum & Maximum & Mean & SD & Paired t-value & P-value & $\%$ \\
\hline \multirow{2}{*}{ IV Sucrose } & Before & 22 & 32 & 26.36 & 2.16 & \multirow{2}{*}{-14.54} & \multirow{2}{*}{$\begin{array}{l}<0.01 \\
\text { HS }\end{array}$} & \\
\hline & After & 30 & 36 & 32.06 & 1.65 & & & $21 \%$ \\
\hline
\end{tabular}

Adverse effects were $14 \%$ in the study group. Thrombophlebitis and Pain at the site of injection were the adverse effects seen with iron sucrose injections. Though adverse effects were less with I.V iron sucrose it was not statistically significant $(\mathrm{P}=0.09)$ [Applied Chisquare test: Chi-square value $=2.95]$.

\section{DISCUSSION}

Iron deficiency anaemia is the most common and important public health problem throughout the world and in India, affecting 35-75\% (average 56\%) of pregnant women in developing countries and $18 \%$ of women from industrialized countries. Anaemia is estimated to contribute to $20 \%$ of all maternal deaths and $9 \%$ of perinatal mortality. Anaemia results in increased number of preterm births, IUGR, PPH, failure of lactation and increased risk of infections in post partum period. Hence prevention and correction of anaemia during pregnancy is vital for safe motherhood.

The traditional treatments, i.e., oral iron therapy and blood transfusion, involve significant drawbacks. High doses of oral iron frequently cause side effects, and noncompliance is common. Administration of oral iron supplementations is not sufficient enough in order to treat anaemia effectively. Due to limited absorption, the gastrointestinal symptoms and the poor compliance for long term treatment of the patients.

As far as blood transfusions are concerned, because of the risk of infection (bacterial, viral, prions) and immune modulation associated with allergenic blood products, especially in this young and otherwise healthy 
population, transfusions are used only in the most severe cases and particularly in life threatening situations. Therefore, intravenous iron has been considered as an alternative in the management of iron deficiency anaemia. This study was conducted in Obstetrics and Gynaecology Department of Government General Hospital, Vijayawada, Andhra Pradesh.

A total of 61 antenatal women were selected and recruited in the study among them only 50 were fit into the study. Majority of women were in the age group of 22-25 years. Mean age of the patients in other studies were approximately similar to present study.

In all other studies maximum number of patients were primigravidas. In the present study $56 \%$ were primi gravidas ( $\mathrm{P}-$ Value $<0.01$ and Chi square value- 39.12) these findings are significant. This is explained by high prevalence of iron deficiency anaemia in adult non pregnant women, when these anaemic women become pregnant their anaemia will be aggravated by increased need of iron during pregnancy, and it is important to screen iron deficiency anaemia in all non pregnant child bearing age group women as recommended by Centre for Disease Control and Prevention.

In the present study the mean gestational age at the time of inclusion in the study group is comparable (29.5 \pm 2$)$ to the mean gestational age in the study by Aggarwal Rohina $\mathrm{S}$ et al where it was $28.2 \mathrm{wks}$. The mean baseline MCV was $69.7 \mathrm{fl} /$ cell. Post treatment MCV after 4 weeks showed an average rise of $8.2 \mathrm{fl} /$ cell ( $\mathrm{p}$ value $<0.01$ ), which is statistically significant. ${ }^{14}$

In this study, the mean baseline haemoglobin was $8.16 \mathrm{~g} / \mathrm{dl}$. Whereas, Post treatment haemoglobin after 4 weeks showed a mean value of $10.66 \mathrm{gm} / \mathrm{dl}$ ( $\mathrm{p}$ value $<0.01$, which is statistically significant. In the present study, the average rise of haemoglobin is $2.5 \mathrm{~g} / \mathrm{dl}$ ( $\mathrm{P}$ Value <0.01). Therefore the overall increase in haemoglobin is good with IV iron. This is similar to the study by Aggarwal Rohina $S$ et al, where the average rise of haemoglobin was $5.03 \mathrm{~g} / \mathrm{dl}$ in intravenous group. ${ }^{14}$

In the study of Prashant $\mathrm{S}$. Kharde et al, baseline haemoglobin was $7.6 \mathrm{~g} / \mathrm{dl}$ and $7.5 \mathrm{~g} / \mathrm{dl}$ in oral and IV groups respectively. The average rise of haemoglobin was $3.54 \mathrm{~g} / \mathrm{dl}$ and $5.3 \mathrm{~g} / \mathrm{dl}$ in oral and IV group respectively. ${ }^{15}$ In another study done by Momen. AI et al in 1996, has shown baseline $\mathrm{Hb} 7.58$ and $7.66 \mathrm{~g} \%$ and MCV 68.6 and $70.8 \mathrm{fl} /$ cell in IV and oral group respectively. After $4 \mathrm{wks} \mathrm{Hb} \%$ increased to 12.8 and $11.1 \mathrm{~g} \%$ and MCV increased to 82.6 and $74.9 \mathrm{fl}$ in IV and oral group respectively. In both studies, no major side effects were seen. ${ }^{16}$

With all these studies, it was evident that the rise in haemoglobin level is effective with Intravenous iron Sucrose. This can be explained by the fact that absorption of iron is better when given intravenously. The mean base line haematocrit (PCV) is $26.36 \%$ and after treatment mean PCV was improved to $32.6 \%$ (P value $<0.01$ ). An average rise of $4 \%$ was observed in the study group. paired $\mathrm{T}$ value was -14.54 . This is statistically significant.

There were minimal side effects in the study group. Only $14 \%$ of women had minimal side effects like pain at the injection site, and mild thrombophlebitis. $\mathrm{P}$ value $=0.09$ indicate that these adverse effects were not significant. Similar observations were reported in other studies like Prashant S. Kharde et al, Bayoumeu F et al and Khurshid Shabbir Raja et al without serious adverse effects. ${ }^{15,17,18}$

This study is comparable with other two studies. In a study done by Agarwal Rohina $\mathrm{S}$ et al in 2010, showed baseline $\mathrm{Hb} 6.2 \mathrm{~g} \%$ and $5.95 \mathrm{~g} \%$, Haematocrit 18.8 and $17.8 \%$, MCV 71.28 and $70.1 \mathrm{fl}$ in IV and oral group respectively. After 4 wks, $\mathrm{Hb} \%$ increased to 11.3 and $10.26 \mathrm{~g} \%$, Haematocrit increased to 33.9 and $30.77 \%$ and MCV increased to 93 and $85.8 \mathrm{fl}$ in IV and oral group respectively. ${ }^{14}$

Thus, it can be inferred from this study that, intravenous iron sucrose has shown improvement in haemoglobin levels, MCV and PCV which showed good efficacy and minimal adverse effects. As most of the antenatal women attending government hospitals belong to low socio economic status, the drug iron sucrose if made available in government hospitals then there can be promising results in treatment of moderate anaemia in antenatal women.

\section{Limitations}

- Sample size in this study was small when compared to the prevalence of this most common disease.

- One ampoule of iron sucrose injection containing $100 \mathrm{mg}$ of iron, costs around Rs.300. As most of the antenatal women attending government hospitals belong to lower socio economic group, the high cost of iron sucrose may not be affordable by them.

- Certain investigations like TIBC and serum iron could not be done as they were not available in government and are very expensive in private labs.

\section{CONCLUSION}

The present study showed that treatment of anaemia with intravenous iron sucrose would increase the haemoglobin considerably. This study proved that iron sucrose when given intravenously there was a rapid improvement in anaemia. IV iron sucrose was proved to be safe with minimal side effects. A superior tolerability profile and a better efficacy profile, strongly suggest that it can be considered as an alternative drug for treatment of moderate anaemia in antenatal women to blood transfusion. However further studies in large patient populations are required to confirm and strengthen the present study. 


\section{ACKNOWLEDGMENTS}

Authors would like to acknowledge the support of the Professor and HOD of OBG, the colleagues in Pharmacology Department and Statistician who helped in completion and success of the study.

Funding: No funding sources

Conflict of interest: None declared

Ethical approval: The study was approved by the Institutional Ethics Committee of Siddhartha Medical College, Vijayawada, Andhra Pradesh

\section{REFERENCES}

1. UNICEF\UNO $\backslash W H O$ GENEVA. Iron deficiency anaemia, assessment, prevention and control, 2001.

2. Noronha JA, Bhaduri A, Bhat VH. Prevalence of anemia among pregnant women: A community-based study in Udupi (D.t), Health and Population Perspectives and Issues. 2008;31(1):31-40.

3. Haider BA, Olofin I, Wang M, Spiegelman D, Ezzati M, Fawzi WW. Anaemia, prenatal iron use, and risk of adverse pregnancy outcomes: systematic review and Meta-analysis. BMJ. 2013 June;346:f3443.

4. Ivan EA, Mangaiarkkarasi A. Evaluation of Anaemia in Booked Antenatal Mothers during the Last Trimester. Journal of Clinical and Diagnosticresearch. 2013;7(11):2487-90.

5. Jiji DB, Rajagopal K. A Study to assess the pregnant women the knowledge and risk factors of anaemia among the pregnant women selected and attending Healthcare facilities in Sebha, Libya. Journal of Science. 2014;4(1):19-22.

6. Patra S, Pasrija S, Trivedi SS, Puri M. Maternal and Perinatal outcome in patients with severe anaemia in pregnancy. International Journal of Gynaecology and obstetrics. 2005;91:164-5.

7. Kalaivani K. Prevalence and consequences of anaemia in pregnancy. Indian J Med Res. 2009 Nov;130(5):627-33.

8. Scholl TO. Iron status during pregnancy: setting the stage for mother and infant. Am J. Clinc Nutr. 2005;81:1218S-22S.
9. Scot BS, George MR. Parental iron therapy option. Am J. 2004;76:74-8.

10. Chandler G, Harchowal J, Macdougall IC. Intravenous iron sucrose: establishing a safe dose. Am J Kidn Dis. 2001;38:988-91.

11. Protocol for the use of IV iron sucrose - Venofer ${ }^{\circledR}$ Page 2 of 11 Author: Transfusion practitioner VI.0 Approved by D\&TC 23 January 2008.

12. Dutta DC. Medical illness complicating pregnancy, Textbook of Obstetrics, $6^{\text {th }}$ Edition. [Ed Konar H] The central Book Agency Pvt Ltd. Culcutta; 2004:262- 271.

13. Dewan B, Philipose N, Balasubramanian A. Assessment of intravenous Iron Sucrose in the Management of Anemia in Gynecological and Obstetrical Practice. Obstet Gynaecol India. 2012 Jun;62(3):281-5.

14. Aggarwal RS, Mishra VV, Panchal NA, Patel NH, Deshchougule VV, Jasani AF. Evaluation of iron sucrose and oral iron in the management of Iron Deficiency Aaemia in pregnancy NJCM. 2012;93:415-16.

15. Kharde PS, Bangal VB, Panicker KK. Comparative study of intravenous iron sucrose versus oral iron therapy in postpartum period. IJBAR. 2012;89:10208 .

16. Momen AI, Meshariet AK. Intravenous Iron sucrose complex in the treatment of iron deficiency anemia during pregnancy. Eur J Obstet Gynecol Reprod Biol. 1996;69:121-4.

17. Raja KS. Intravenous iron sucrose complex in iron deficiency anaemia in pregnancy. RWJ. 2003;216:649.

18. Bayoumeu F. Iron therapy in iron deficiency anaemia in pregnancy, intravenous route versus oral route. AM J obstetgynecol. 2002;186:518-212.

Cite this article as: Vundi VR, Pudutha M, Kambar C. A study of efficacy and safety of intravenous iron sucrose for the treatment of moderate anaemia in antenatal women in South India. Int J Basic Clin Pharmacol 2017;6:1655-60. 